\title{
Esophageal Strictures during Treatment with a Proton Pump Inhibitor
}

\author{
Einar Arnbjörnsson"1,2, Torbjörn Backman"1,2 \\ ${ }^{1}$ Department of Pediatric Surgery, Skåne University Hospital, Lund, Sweden \\ ${ }^{2}$ The Institution of Clinical Research, Lund University, Lund, Sweden \\ Email: einar.arnbjornsson@telia.com
}

Received 6 January 2015; accepted 27 January 2015; published 29 January 2015

Academic Editor: Cora Jonkers, Academic Medical Centre Amsterdam, The Netherlands

Copyright (C) 2015 by authors and Scientific Research Publishing Inc.

This work is licensed under the Creative Commons Attribution International License (CC BY). http://creativecommons.org/licenses/by/4.0/

(c) (i) Open Access

\begin{abstract}
Background: The development of esophageal stricture during treatment with high dose chemotherapeutic agents is well known and documented in the literature. With the introduction of proton pumps inhibitors (PPI), the gastroesophageal reflux disease (GERD) induced stricture has shown significant improvement. The aim of this report is to remind of the fact that the chemotherapy induced strictures show poor response and their treatment is still a challenge. Case presentation: Here, we reported a boy with Down syndrome and congenital heart disease who developed acute lymphoblastic leukemia and subsequent esophageal stricture during treatment with a PPI. Conclusion: It is important to be aware of this potential complication of gastroesophageal reflux or antineoplastic treatment, even in cases thought to be adequately treated with a proton pump inhibitor, and that the start of PPI's is also the start of an evaluation of the use of this medication.
\end{abstract}

\section{Keywords}

Gastroesophageal Reflux (GER), Omeprazole, Esophagitis, Esophageal Stricture, Proton Pump Inhibitor (PPI), An Antineoplastic Treatment

\section{Introduction}

Proton pump inhibitors (PPIs) are widely used to treat esophagitis in patients with gastroesophageal reflux (GER) or gastroesophageal reflux disease (GERD) to prevent complications such as esophageal stricture and bleeding [1] [2].

The development of esophageal stricture during treatment with high dose chemotherapeutic agents is well 
known and documented in the literature. With the introduction of proton pumps inhibitors (PPI), the gastroesophageal reflux disease (GERD) induced stricture has shown significant improvement but the chemotherapy induced strictures show poor response and its treatment is still a challenge. Although esophageal stricture rarely occurs since the introduction of PPI therapy, there are some known risk factors for failure of PPI therapy including trisomy 21, chemotherapy, and gastrostomy.

Here, we reported a boy with Down syndrome and congenital heart disease who developed acute lymphoblastic leukemia (ALL) and an esophageal stricture due to GER or antineoplastic treatment while also receiving treatment with a PPI (omeprazole). We are not aware of any similar reports in the literature.

\section{Case Report}

The patient was a boy with Down syndrome and a congenital cardiac malformation. The history is summarized in Table 1. At 4 years of age he underwent surgery for the cardiac malformation, and at 9 years of age he developed acute lymphoblastic leukemia (ALL). His ALL treatment consisted of induction based on the Nordic Society of Pediatric Hematology, Oncology ALL-2000 protocol, used at that time, followed by consolidation based on the 2003 protocol of the European intergroup study on postinduction treatment of Philadelphia-chromosome-positive ALL with imatinib.

During ALL treatment, the boy developed stomatitis and severe nutritional problems. He received nutrition through a nasogastric tube, which was poorly tolerated and vomited frequently. He had not shown evidence of GER or GERD before initiation of chemotherapy. He underwent the following diagnostic and therapeutic procedures:

- Plain radiography of the stomach and esophagus, which revealed GER. Radiography is not a standard approach to the diagnosis of GER, but was used in this case because it can diagnose the complications of GERD, including esophageal dilatation and stricture.

- GER was confirmed using a 24-hour pH monitoring test that revealed moderate reflux (reflux index, 13.6\%). The reflux index is defined as percent of investigation time with a $\mathrm{pH} \leq 4.0$; an abnormal reflux index is $>10 \%$. Antireflux surgery for GER was not thought indicated or advisable because the patient was undergoing chemotherapy for ALL. Furthermore, PPI treatment was not considered, because of the risk of fungal infection.

- The boy underwent video-assisted gastrostomy (VAG) [3] for placement of a Mic-Key ${ }^{\circledR}$ gastrostomy device (Ballard Medical Products; Utah, USA).

- Gastroscopy was performed during the procedure [4] and did not reveal signs of esophagitis.

The gastrostomy procedure and the postoperative course were uneventful. The patient occasionally developed leakage, granulomas, and minor infections around the gastrostomy site, especially when he was undergoing intensive

Table 1. Case history summary of a pediatric patient with Down syndrome and congenital heart disease who developed an esophageal stricture during treatment with a proton pump inhibitor.

\begin{tabular}{|c|c|c|c|c|}
\hline Age & & & & \\
\hline 4 years & Surgery & ongenital cardiac malformation & & \\
\hline 9 years & ALL $^{*}$ & Treatment for ALL started & & \\
\hline+2 months & $\begin{array}{c}\text { GER }^{* *} \text { diagnosed } \\
\text { Gastrostomy } \\
\mathbf{1}^{\text {st }} \text { Gastroscopy }\end{array}$ & & No esophagitis & \\
\hline +8 months & $\begin{array}{l}\text { Severe esophageal gastrointestinal bleeding } \\
\qquad \mathbf{2}^{\text {nd }} \text { Gastroscopy }\end{array}$ & & Esophagitis & $\mathrm{PPI}^{* * *}$ started \\
\hline 10 years & Symptoms of esophageal stricture & & & \\
\hline +1 month & $\begin{array}{l}3^{\text {rd }} \text { Gastroscopy } \\
\text { Dilatation of stricture }\end{array}$ & & $\begin{array}{c}\text { Stricture } \\
\text { No esophagitis }\end{array}$ & \\
\hline 13 years & End of follow up & & & \\
\hline
\end{tabular}

${ }^{*}$ ALL: Acute lymphoblastic leukemia.
${ }^{* *}$ GER: Gastroesophageal reflux.

${ }^{* * * *}$ PPI: Proton Pump Inhibitors. 
cytostatic treatment. These problems were always successfully treated by conservative management [5].

Six months after the gastrostomy procedure, while still undergoing ALL chemotherapy, the patient was admitted to the emergency department for severe bleeding from the gastrostomy. His hemoglobin level was less than $60 \mathrm{~g} / \mathrm{L}$, and he received blood transfusions. The patient was treated medically using omeprazole (Losec MUPS), administered through the gastrostomy button, and intravenous desmopressin (Octostim) and tranexamic acid (Cyklokapron), which resolved the bleeding. The volume in the Mic-Key balloon was increased. The balloon was expanded to compress the abdominal wall around the gastrostomy site, because the bleeding was thought to be associated with the gastrostomy. Copious bleeding from a gastrostomy canal that requires blood transfusion has not been reported as a complication of VAG [5].

Gastroscopy using a 9-mm video endoscope (provided by Karl Storz endoscope) was performed, and revealed severe esophagitis without deep ulcerations that involved the distal $6 \mathrm{~cm}$ of the esophagus. The diagnosis was verified by biopsy. There was no sign of inflammation or visible bleeding in the stomach or near the opening of the gastrostomy. A repeat 24-hour pH monitoring test was negative for GER. There were no clinical or biopsy-proven signs of fungal infection, Helicobacter pylori, eosinophilic, or herpes virus esophagitis. The patient continued receiving oral omeprazole $(0.8 \mathrm{mg} / \mathrm{kg}$ once daily, via the gastrostomy button).

Five months later, the patient started to vomit everything he received orally but nothing given to him through the gastrostomy button. We presumed that the patient was reliably receiving his medications, because he underwent frequent regular monitoring because of his ALL treatment, which consisted of maintenance therapy using 6-mercaptopurine (Puri-netol tablets) and methotrexate (Methotrexate tablets). The omeprazole dose was doubled to $40 \mathrm{mg}$ daily administered through the gastrostomy button.

The patient underwent gastroscopy using a 6-mm video endoscope, which revealed a severe stricture in the distal part of the esophagus, about $4 \mathrm{~cm}$ from the cardia of the stomach, but no esophagitis (Figure 1). The stricture did not allow passage of the 6-mm video endoscope. The stricture was treated using balloon catheter dilatation (Figure 2). Calibrations using the same type of balloon catheter were performed at 2 and 4 weeks after the dilatation procedure. High-dose omeprazole administration was continued. No further bleeding was seen during 26 months of follow up.

\section{Discussion}

Reports on the prevalence of esophageal reflux disease in the pediatric population, along with information on its complications and treatment, have not described similar cases where esophageal stricture occurred during treatment with a PPI [6] [7]. Esophageal stricture rarely occurs since the introduction of PPI treatment, but has still been found in 4\% of patients undergoing endoscopy [8]. GER, GERD, and gastroesophageal motility disorders are common in children with trisomy 21 [9]. Children with trisomy 21 and congenital heart disease, such as our patient, are at increased risk of gastroesophageal reflux [10].

There have been several case reports of Barrett's esophagus in patients with acute leukemia or Crohn disease who received chemotherapy [11] or methotrexate [12], respectively. Our patient with Down syndrome and ALL was also undergoing treatment with 6-mercaptopurine and methotrexate at the time he developed esophageal stricture. Gastrointestinal and/or oral ulcerations are very rare complications of 6-mercaptopurine, occurring in less than 1 out of 100,000 patients. The product information on methotrexate reports that it causes stomatitis in $<1 \%$ of treated patients. Therefore, a deleterious effect of the patient's medications on his esophageal mucosa cannot be excluded [13].

The response of the individual patient to PPIs administered either orally or intravenously, especially upon the initiation of treatment, is known to vary greatly [14]. A variable response to PPI has been found to be reduced by the intravenous administration of higher doses of PPI [15], which is why our patient received high-dose omeprazole. However, in that study [15], the variable response was associated with the H. pylori status of the participants, and our patient was negative for $H$. pylori infection. It may be possible that children with Down syndrome respond differently to PPI treatment compared to children without Down syndrome [16].

A potential bias in this report is the administration of the Losec MUPS. If the capsules are opened and the granulate is given directly in the gastrostomy the effect of the omeprazole could be different and less effective. In this child the liquid PPI's might have been a better solution to treat the acid flow in the esophagus.

We did not determine the concentration of omeprazole in the peripheral blood or the mucosa of the stomach of our patient to monitor the absorption of his dose of omeprazole. Determining the efficacy of omeprazole treatment using 24-h testing of esophageal $\mathrm{pH}$ is sufficient for monitoring the efficacy of omeprazole treatment, 


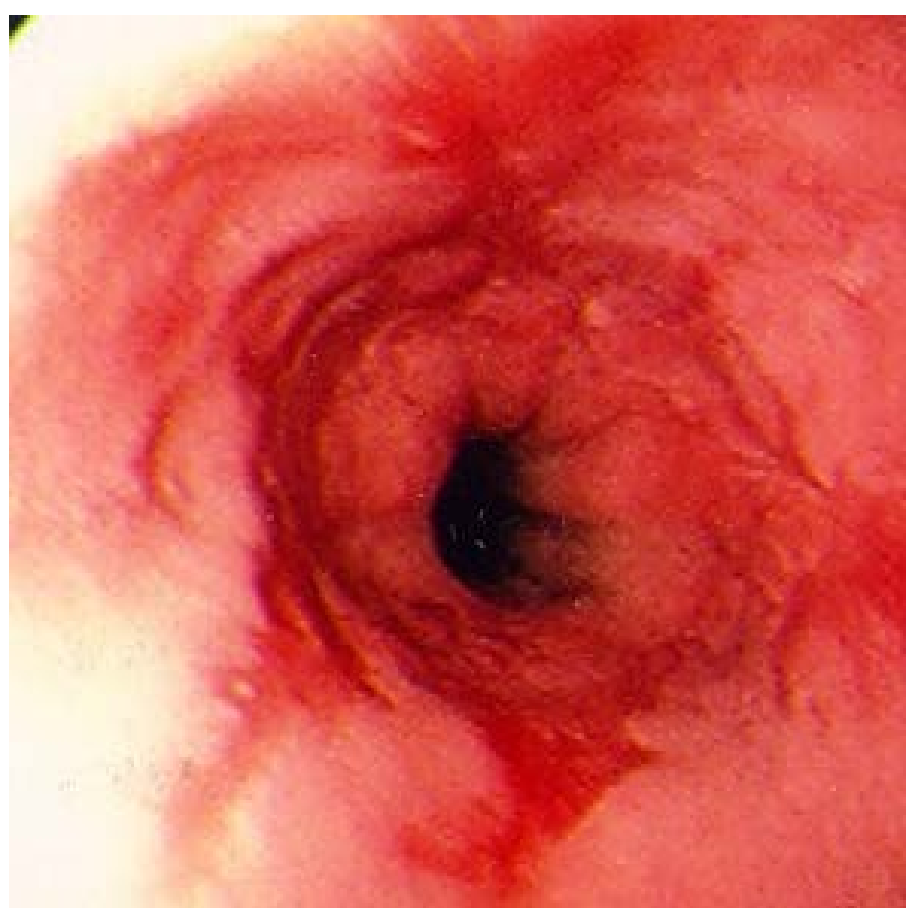

Figure 1. Esophageal stricture viewed from above through the endoscope.

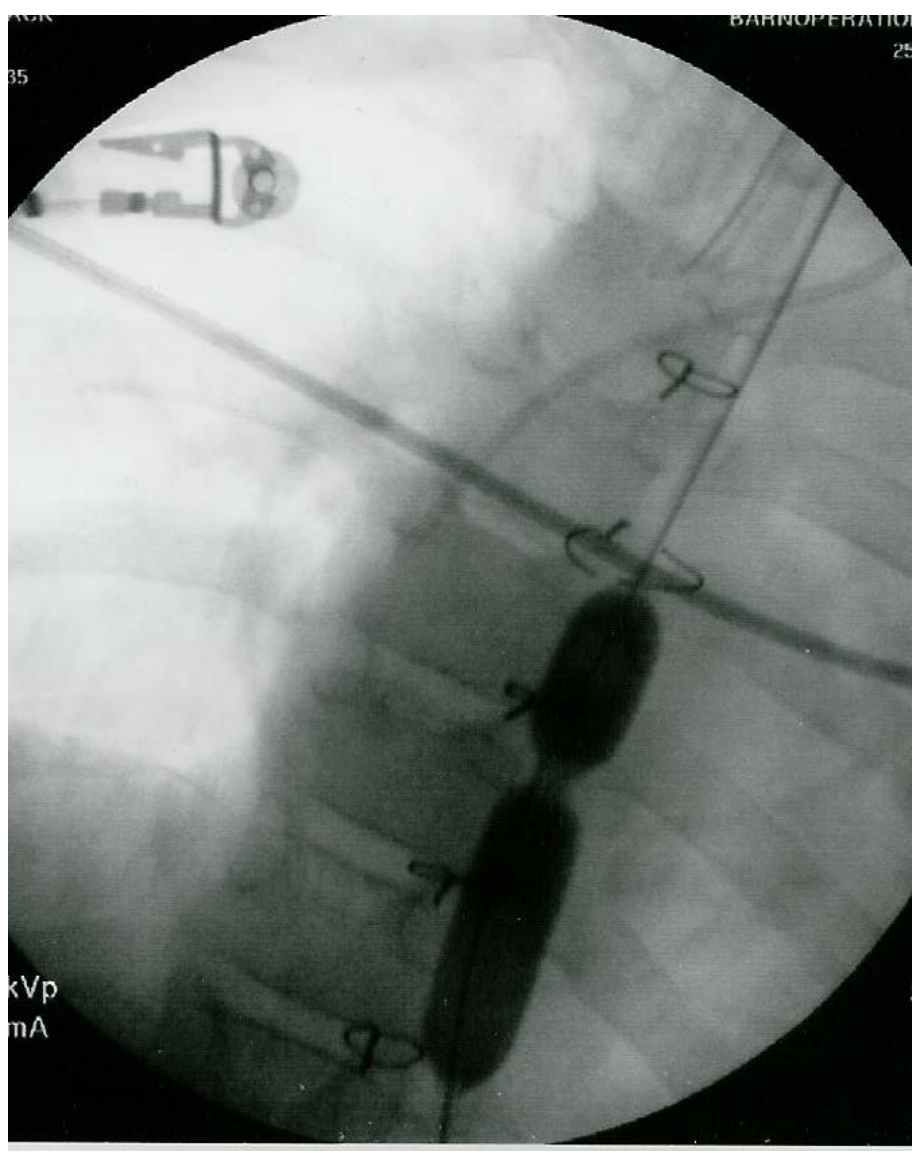

Figure 2. X-ray film showing the stricture in the esophagus. A 12-mm balloon catheter is in the esophagus. 
but was also not performed in this case. However, the resolution of our patient's esophagitis, which was found during the second gastroscopy, suggests that the dose of omeprazole was adequate.

It could be postulated that esophageal fibrosis may have begun before the first gastroscopy, leading to stricture formation despite adequate PPI treatment. We did not observe any deep ulcerative lesions in the esophagus during that gastroscopy. It is important to note that the healing process of deep esophageal ulcerations involves scarring, which is the basis for stricture development in the esophagus. Since no deep ulcerations were found, we do not believe that early development of fibrosis was the cause of the stricture.

The treatment of ALL probably accounts for the appearance of GER symptoms following the initiation of chemotherapy. The diagnosis of GER was established 2 months after ALL chemotherapy was started, and was based on abdominal radiography and 24-h esophageal $\mathrm{pH}$ testing that showed moderate reflux (reflux index, 13.6\%). Therefore, GER was diagnosed before the patient underwent gastrostomy.

We cannot not provide definitive evidence, that the esophageal stricture of our patient was a result of ineffective PPI treatment, and not a consequence of chemotherapy.

The gastroscopy was initially performed to exclude esophagitis when our patient developed problems during the initiation of chemotherapy [9]. Omeprazole was begun when GER was diagnosed to prevent further complications. Therefore, we believe that the esophageal stricture did not develop as a consequence of delayed antireflux treatment, but because the PPI treatment failed.

There is a question regarding whether GER can be a result of the gastrostomy procedure. A previously published study of children undergoing VAG and esophageal 24-h pH measurements pre- and postoperatively did not demonstrate increased acid reflux after the surgery [17]. The authors of a systematic review assessing the association of GERD with percutaneous endoscopic gastrostomy (PEG) procedures [18] concluded that there was no current evidence that PEG improved or aggravated GERD. Regardless of reports of cohort studies and meta-analyses that have concluded that GER does not increase after a gastrostomy procedure, it cannot be ruled out that GER will not develop in individual cases. However, as mentioned previously, our patient was not assessed for changes in the reflux index.

In summary, we believe that the esophageal stricture of our patient developed during his treatment with a PPI for the following reasons:

- The boy was not reported to have any GER symptoms before he developed ALL.

- The first gastroscopy, performed 2 months after the initiation of chemotherapy for ALL, did not reveal esophagitis or stricture.

- GER was verified before the patient underwent VAG.

- PPI treatment was started when the patient was admitted for esophageal bleeding.

- Despite PPI treatment for 5 months, the boy developed an esophageal stricture as a result of GER.

\section{Conclusion}

We conclude that it is important to be aware of the possible development of an esophageal stricture in patients with esophagitis, even when they are undergoing apparently adequate treatment with a PPI for GER. Although esophageal stricture rarely occurs since the introduction of PPI therapy, the case presents some known risk factors for failure of PPI therapy: trisomy 21, chemotherapy, and gastrostomy.

\section{Acknowledgements}

To BioMed Proofreading LLC.

\section{References}

[1] Cardile, S. and Romano, C. (2012) Clinical Utility of Esomeprazole for Treatment of Gastroesophageal Reflux Disease in Pediatric and Adolescent Patients. Adolescent Health, Medicine and Therapeutics, 2012, 27-31. http://dx.doi.org/10.2147/AHMT.S23193

[2] Freston, J.W. (2004) Therapeutic Choices in Reflux Disease: Defining the Criteria for Selecting a Proton Pump Inhibitor. American Journal of Medicine, 117, 14S-22S.

[3] Andersson, L., Mikaelsson, C., Arnbjornsson, E. and Larsson, L.T. (1997) Laparoscopy Aided Gastrostomy in Children. Annales chirurgiae et gynaecologiae, 86, 19-22. 
[4] Backman, T., Sjövie, H., Kullendorff, C.M. and Arnbjörnsson, E. (2010) Continuous Double U-Stitch Gastrostomy in Children. European Journal of Pediatric Surgery, 20, 14-17. http://dx.doi.org/10.1055/s-0029-1238316

[5] Arnbjornsson, E., Larsson, L.T. and Lindhagen, T. (1999) Complications of Laparoscopy-Aided Gastrostomies in Pediatric Practice. Journal of Pediatric Surgery, 34, 1843-1846. http://dx.doi.org/10.1016/S0022-3468(99)90327-5

[6] Dorlöchter, L., Kolsrud, E., Olafsdottir, E., Fluge, G., Rosendahl, K. and Hatlebakk, J. (2000) Esophageal Stricture as a Complication of Gastroesophageal Reflux in Children. Tidsskr Nor Laegeforen, 120, 187-189.

[7] Faubion Jr., W.A. and Zein, N.N. (1998) Gastroesophageal Reflux in Infants and Children. Mayo Clinic Proceedings, 73, 166-173.

[8] Guda, N.M. and Vakil, N. (2004) Proton Pump Inhibitors and the Time Trends for Esophageal Dilation. American Journal of Gastroenterology, 99, 797-800. http://dx.doi.org/10.1111/j.1572-0241.2004.04169.x

[9] Faubion Jr., W.A., Perrault, J., Burgart, L.J., Zein, N.N., Clawson, M. and Freese, D.K. (1998) Treatment of Eosinophilic Esophagitis with Inhaled Corticosteroids. Journal of Pediatric Gastroenterology \& Nutrition, 27, 90-93. http://dx.doi.org/10.1097/00005176-199807000-00016

[10] Thompson, L.D., McElhinney, D.B., Jue, K.L. and Hodge, D. (1999) Gastroesophageal Reflux after Repair of Atrioventricular Septal Defect in Infants with Trisomy 21: A Comparison of Medical and Surgical Therapy. Journal of Pediatric Surgery, 34, 1359-1363. http://dx.doi.org/10.1016/S0022-3468(99)90011-8

[11] Dahms, B.B., Greco, M.A., Strandjord, S.E. and Rothstein, F.C. (1987) Barrett's Esophagus in Three Children after Antileukemia Chemotherapy. Cancer, 60, 2896-2900. http://dx.doi.org/10.1002/1097-0142(19871215)60:12<2896::AID-CNCR2820601208>3.0.CO;2-P

[12] Batres, L.A., Gabriel, C.A. and Tsou, V.M. (2003) Methotrexate-Induced Esophagitis in a Child with Crohn Disease. Journal of Pediatric Gastroenterology \& Nutrition, 37, 514-516. http://dx.doi.org/10.1097/00005176-200310000-00021

[13] de Mingo, L., Garcia, C., Morato, P. and Rollan, V. (1999) Barrett's Esophagus and Chemotherapy, a Case Report. European Journal of Pediatric Surgery, 9, 327-330. http://dx.doi.org/10.1055/s-2008-1072274

[14] Labenz, J., Peitz, U., Leusing, C., Tillenburg, B., Blum, A.L. and Borsch, G. (1997) Efficacy of Primed Infusions with High Dose Ranitidine and Omeprazole to Maintain High Intragastric $\mathrm{pH}$ in Patients with Peptic Ulcer Bleeding: A Prospective Randomised Controlled Study. Gut, 40, 36-41. http://dx.doi.org/10.1136/gut.40.1.36

[15] Netzer, P., Gaia, C., Sandoz, M., Huluk, T., Gut, A., Halter, F., Husler, J. and Inauen, W. (1999) Effect of Repeated Injection and Continuous Infusion of Omeprazole and Ranitidine on Intragastric $\mathrm{pH}$ over 72 Hours. The American Journal of Gastroenterology, 94, 351-357. http://dx.doi.org/10.1016/S0002-9270(98)00738-2

[16] Eltumi, M., Brueton, M.J. and Francis, N. (1999) Diagnosis of Helicobacter pylori Gastritis in Children Using the 13C Urea Breath Test. Journal of Clinical Gastroenterology, 28, 238-240. http://dx.doi.org/10.1097/00004836-199904000-00010

[17] Plantin, I., Arnbjörnsson, E. and Larsson, L.T. (2006) No Increase in Gastroesophageal Reflux after Laparoscopic Gastrostomy in Children. Pediatric Surgery International, 22, 581-584. http://dx.doi.org/10.1007/s00383-006-1707-7

[18] Noble, L.J., Dalzell, A.M. and El-Matary, W. (2012) The Relationship between Percutaneous Endoscopic Gastrostomy and Gastro-Oesophageal Reflux Disease in Children: A Systematic Review. Surgical Endoscopy, 26, 2504-2512. http://dx.doi.org/10.1007/s00464-012-2221-8 
Scientific Research Publishing (SCIRP) is one of the largest Open Access journal publishers. It is currently publishing more than 200 open access, online, peer-reviewed journals covering a wide range of academic disciplines. SCIRP serves the worldwide academic communities and contributes to the progress and application of science with its publication.

Other selected journals from SCIRP are listed as below. Submit your manuscript to us via either submit@scirp.org or Online Submission Portal.
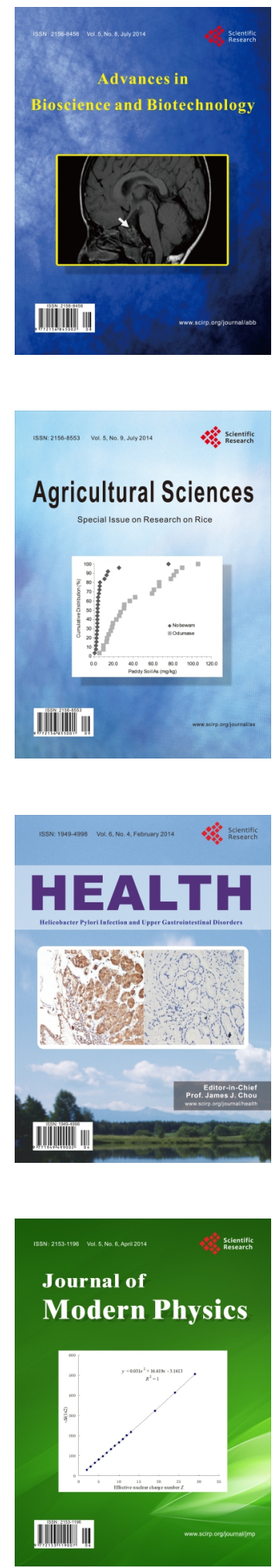
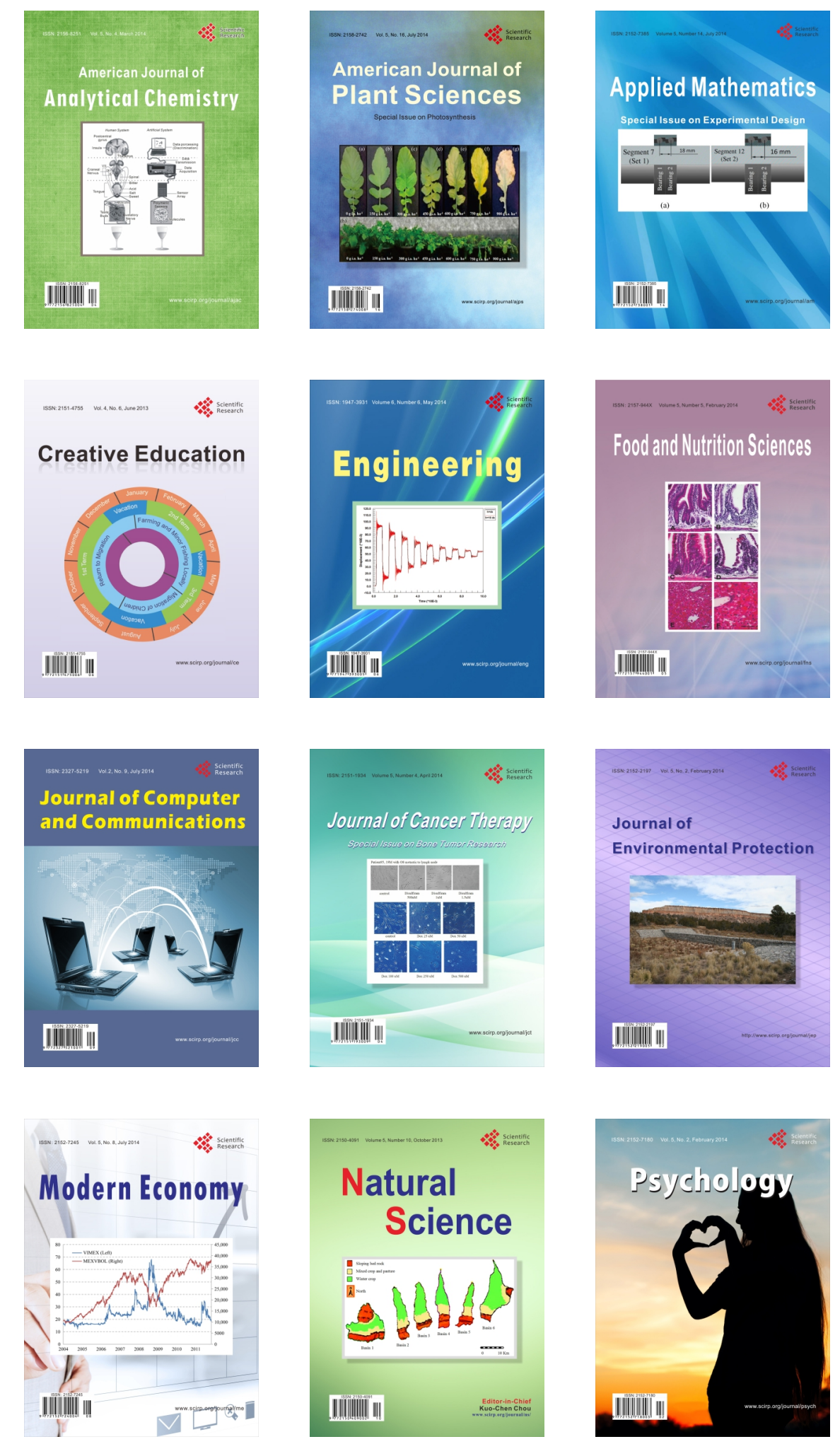